\title{
Cyclooxygenase-1 as the Main Source of Proinflammatory Factors After Sodium Orthovanadate Treatment
}

\author{
Jan Korbecki • Irena Baranowska-Bosiacka • Izabela Gutowska • \\ Katarzyna Piotrowska • Dariusz Chlubek
}

Received: 22 October 2014 / Accepted: 4 November 2014 / Published online: 15 November 2014

(C) The Author(s) 2014. This article is published with open access at Springerlink.com

\begin{abstract}
Vanadium is a metal present in air pollution. Its compounds may have both anticancer and carcinogenic properties. Vanadium compounds are tested in treatment of diabetes and cancer. An important research direction aimed at better understanding of the mechanisms of action of the vanadium compounds is a more detailed insight into their impact on inflammatory reactions. The aim of this study was to examine the effect of micromolar concentrations of sodium orthovanadate, $\mathrm{Na}_{3} \mathrm{VO}_{4}$, on the activity and expression of cyclooxygenases: COX-1 and COX-2. PMA-activated THP1 macrophages were incubated in vitro for $48 \mathrm{~h}$ with micromolar concentrations of sodium orthovanadate. As shown by an ELISA assay, sodium orthovanadate increases the quantity of prostaglandin $\mathrm{E}_{2}$ being released into the medium in a dosedependent manner as well as impacts the quantity of the stable metabolite of thromboxane $\mathrm{A}_{2}$ : thromboxane $\mathrm{B}_{2}$. The use of a COX-2 inhibitor, NS-398, revealed that this effect was independent of changes in the activity of COX-2. Western blotting analysis showed that sodium orthovanadate increased the expression of COX-2 when used with NS-398. Quantitative real-time PCR measurements of mRNA levels of genes PTGS1 and PTGS2 revealed no effect of the tested vanadium compound on the levels of analyzed transcripts.
\end{abstract}

J. Korbecki $(\bowtie) \cdot$ I. Baranowska-Bosiacka $\cdot$ D. Chlubek Department of Biochemistry and Medical Chemistry, Pomeranian Medical University, Powstańców Wlkp. 72 Av., 70-111 Szczecin,

Poland

e-mail: jan.korbecki@onet.eu

I. Gutowska

Department of Biochemistry and Human Nutrition, Pomeranian Medical University, Broniewskiego 24 Str., 71-460 Szczecin, Poland

K. Piotrowska

Department of Physiology, Pomeranian Medical University, Powstańców Wlkp. 72 Av., 70-111 Szczecin, Poland
Keywords Prostaglandin $\cdot$ Cyclooxygenase $\cdot$ Macrophage Vanadium $\cdot$ Sodium orthovanadate

\begin{tabular}{|c|c|}
\hline \multicolumn{2}{|c|}{ Abbreviations } \\
\hline $15 \mathrm{~d}-\mathrm{PGJ}_{2}$ & 15 -deoxy- $\Delta^{12,14}$-prostaglandin $\mathrm{J}_{2}$ \\
\hline AP-1 & Activator protein 1 \\
\hline BMOV & Bis(maltolato)oxovanadium(IV) \\
\hline CBP & cAMP response element \\
\hline CREB & cAMP response element-binding protein \\
\hline COX-1 & Cyclooxygenase-1 \\
\hline COX-2 & Cyclooxygenase- 2 \\
\hline $\mathrm{cPLA}_{2}$ & Cytosolic phospholipase $\mathrm{A}_{2}$ \\
\hline $\mathrm{EP}_{2}$ & Prostaglandin $\mathrm{E}_{2}$ receptor- 2 \\
\hline $\mathrm{EP}_{4}$ & Prostaglandin $\mathrm{E}_{2}$ receptor- 4 \\
\hline GLUT-4 & Glucose transporter type 4 \\
\hline HUVEC & Human umbilical vein endothelial cells \\
\hline $\mathrm{Na}_{3} \mathrm{VO}_{4}$ & Sodium orthovanadate \\
\hline Nrf2 & Nuclear factor erythroid 2-related factor-2 \\
\hline NSAID & Nonsteroidal anti-inflammatory drugs \\
\hline $\mathrm{PGE}_{2}$ & Prostaglandin $\mathrm{E}_{2}$ \\
\hline PKA & Protein kinase $\mathrm{A}$ \\
\hline PMA & Phorbol myristate acetate \\
\hline $\operatorname{PPAR} \gamma$ & Peroxisome proliferator-activated receptor- $\gamma$ \\
\hline PTP & Protein tyrosine phosphatase \\
\hline qRT-PCR & Quantitative real-time PCR analysis \\
\hline $\mathrm{TXA}_{2}$ & Thromboxane $\mathrm{A}_{2}$ \\
\hline $\mathrm{TXB}_{2}$ & Thromboxane $\mathrm{B}_{2}$ \\
\hline
\end{tabular}

Introduction

Vanadium is a metal present in the polluted air in large urban and industrial agglomerations. Environmental sources of vanadium include soil and pollution from combustion of fossil fuels [1]. Prolonged exposure to vanadium oxide contained in 
the air may cause lung cancers [2]. Also, other inorganic vanadium compounds are known to have carcinogenic properties. The mechanism of action of these compounds has been well studied and proceeds along multiple pathways. Vanadium compounds stimulate proliferation of cells while simultaneously interfering with the course of apoptosis [3]. However, in vitro studies also revealed that the treatment of cancer cells with vanadium compounds caused apoptosis and inhibition of proliferation $[4,5]$. Depending on the expression of p53, vanadium compounds have either carcinogenic or anticancer properties [3].

Molecular mechanisms of action of vanadium compounds are still being studied. Thanks to the easily occurring changes in their oxidation states, vanadium compounds generate reactive oxygen species (ROS) by means of Fenton's reaction or a reaction with oxygen [6]. In addition, compounds in question are structurally similar to phosphate anions. Thus, they may act as protein tyrosine phosphatase (PTP) inhibitors [7]. As a result of inhibition of these enzymes, numerous signaling pathways are activated within cells.

Vanadium compounds are tested in experimental treatment of diabetes as they inhibit PTP1B, among their other effects [8]. In type 2 diabetes, the activity of this phosphatase is increased, leading to insulin resistance. In addition, vanadium compounds enhance the glucose transport mediated by glucose transporter type 4 (GLUT-4) and the glycogen synthesis, leading to reduced blood glucose levels [9]. However, due to the higher toxicity of inorganic vanadium compounds, organic vanadium derivatives such as bis(maltolato)oxovanadium(IV) (BMOV) are being tested for their potential use in antidiabetic treatment [10].

An important research direction aimed at better understanding of the mechanisms of action of the vanadium compounds is a more detailed insight into their impact on inflammatory reactions. These reactions are associated with numerous disorders. They are important in the course of cancers or atherosclerosis. One of the most important inflammatory processes is the synthesis of prostaglandins and thromboxanes, occurring along cyclooxygenase pathway from arachidonic acid released from membrane phospholipids by means of cytosolic phospholipase $\mathrm{A}_{2}\left(\mathrm{cPLA}_{2}\right)$. In physiological conditions, cyclooxygenase-1 (COX-1) plays an important role in the synthesis of prostaglandin $\mathrm{E}_{2}\left(\mathrm{PGE}_{2}\right)$. The expression of this enzyme is maintained at the constitutive level and is rarely changed. Expression of cyclooxygenase-2 (COX-2) is increased in inflammatory reactions. Increased enzyme levels lead to increased production of prostaglandins.

Increased expression of COX-2 in tumor cells is very important for the natural history of the disease. $\mathrm{PGE}_{2}$ being synthesized by this enzyme disturbs apoptosis and promotes angiogenesis, thus promoting tumor growth [11]. Potential anticancer drugs should be examined for their effects on expression and activity of COX-2 and induction of inflammatory reactions, as this would allow for development of safe therapies.
Considering the above, the aim of this study was to demonstrate the effect of micromolar concentrations of sodium orthovanadate on the development of inflammation in THP-1 macrophage cells by measuring the activity and expression of COX-1 and COX-2 (at both mRNA and protein levels).

\section{Material and Methods}

\section{Cell Culture}

The study was conducted on macrophages obtained from a monocytic line THP-1. Human THP-1 monocytic cells have been widely employed as an in vitro model for investigating the molecular mechanisms underlying monocyte-tomacrophage differentiation [12]. THP-1 cells (ATCC, Rockville, USA) were differentiated into macrophages by administering phorbol myristate acetate (PMA) $[12,13]$ and cultured in RPMI-1640 medium (BIOMED-LUBIN, Poland) supplemented with $10 \%$ FBS without fatty acid (ALAB, Poland), penicillin $(100 \mathrm{U} / \mathrm{mL})$, and streptomycin $(100 \mathrm{mg} /$ $\mathrm{mL}$; Sigma-Aldrich, Poland) at $37{ }^{\circ} \mathrm{C}$ in $5 \% \mathrm{CO}_{2}$. The THP-1 monocytes were treated with $100 \mathrm{nM}$ PMA (Sigma-Aldrich, Poland) for $24 \mathrm{~h}$, and then the adherent macrophages were washed three times with PBS (BIOMED-LUBLIN, Poland) and incubated with sodium orthovanadate $\left(\mathrm{Na}_{3} \mathrm{VO}_{4}\right)$ (SigmaAldrich, Poland) solution with or without specific COX-2 inhibitor NS-398 (Sigma-Aldrich, Poland) at final concentration of $50 \mu \mathrm{M}$ for $48 \mathrm{~h}$ at $37^{\circ} \mathrm{C}$. Incubation time was selected on the basis of results obtained in preliminary experiments. Sodium orthovanadate was used at final concentrations of $80 \mathrm{nM}, 1,4$, and $10 \mu \mathrm{M}$. These concentrations were selected on the basis of in vitro study of cancer cells [5] and study on blood vanadium concentration in Taiwanese students [14]. After incubation, cells were harvested by scraping and a pellet was obtained by centrifugation ( $250 \mathrm{~g}$ for $5 \mathrm{~min}$ ).

The cell count was determined with a Bright Line Hemacytometer (Sigma-Aldrich, Poznan, Poland). Cell viability was examined using a trypan blue dye exclusion method. Cell cultures with viability more than $97 \%$ were used for experiments [15]. Protein concentration was measured by the Bradford method [16].

\section{Measurements of COX-1 and COX-2 Activity}

Cyclooxygenases COX-1 and COX-2 activity were measured in vitro by quantitative measurement of their products: $\mathrm{PGE}_{2}$ and thromboxane $\mathrm{A}_{2}\left(\mathrm{TXA}_{2}\right)$. The cells were incubated for $48 \mathrm{~h}$ with sodium orthovanadate solutions, as described above. $\mathrm{PGE}_{2}$ and $\mathrm{TXA}_{2}$ were extracted from the culture supernatants with the use of Bakerbond SPE columns (J.T. Baker, USA), as described in manufacturer's instructions. The concentrations of $\mathrm{PGE}_{2}$ released were measured spectrophotometrically by using the $\mathrm{PGE}_{2}$ 
enzyme immunoassay kit (Cayman Chemical, USA) according to the manufacturer's protocol. As $\mathrm{TXA}_{2}$ has a short half-life (37 s) and is rapidly hydrolyzed nonenzymatically to its stable derivative thromboxane $\mathrm{B}_{2}\left(\mathrm{TXB}_{2}\right)$, the thromboxane $\mathrm{B} 2$ enzyme immunoassay kit (Cayman Chemical, USA) was used to measure free $\mathrm{TXA}_{2}$ indirectly.

\section{Western Blotting Analysis of COX-1 and COX-2 Expression}

Cells after incubation with sodium orthovanadate were washed with PBS. After scraping, they were lysed with lysing buffer containing protease inhibitor, ethylene-diaminetetra-acetic acid $5 \mathrm{mM}$, sodium dichloroisocyanurate $1 \%$, TRITON-X $1 \%$, sodium orthovanadate $100 \mathrm{mM}$ (Sigma-Aldrich, Poland), and equal amounts of protein were separated in gel electrophoresis and transferred to a nitrocellulose membrane (Thermo Scientific, Pierce Biotechnology, USA) at $157 \mathrm{~mA}$ for $2 \mathrm{~h}$ at room temperature. After blocking the membrane with $5 \%$ non-fat milk in Tris-buffered saline (Sigma-Aldrich, Poland) containing $0.1 \%$ Tween 20 (Sigma-Aldrich, Poland) for all night at $4{ }^{\circ} \mathrm{C}$, it was incubated with primary monoclonal antibodies direct against COX-1 or COX-2 (Santa Cruz Biotechnology, USA) in dilution $1: 200$ with a monoclonal anti- $\beta$-actin (1:5000; Santa Cruz Biotechnology, USA) and next with secondary antibodies (goat anti-mouse IgG HRP; Santa Cruz Biotechnology, USA) in dilution 1:5000. Signals were visualized by chemiluminescence (Thermo Scientific, Pierce Biotechnology, USA). ImageJ 1.410 (NIH, USA) was used to densitometric analysis of bands.

\section{Imaging of COX-1 and COX-2 Immunoexpression}

Expression of COX-1 and COX-2 proteins was examined with confocal microscopy. THP-1 cells were grown on cover glasses in standard in vitro culture conditions. Further, cells were washed with PBS and fixed with $4 \%$ buffered formalin for $15 \mathrm{~min}$ in room temperature. After the fixation and washing with PBS, cells were permeabilized with $0.5 \%$ solution of Triton X-100 in PBS. After washing with fresh portion of PBS, cells were incubated with mouse anti-COX-1 or antiCOX-2 primary antibodies (Santa Cruz Biotechnology, USA) in dilution 1:50, in $4{ }^{\circ} \mathrm{C}$, overnight, and then washed and incubated with secondary antibody: anti mouse IgG FITC conjugated (Sigma-Aldrich, Poland) in dilution 1:60 in antibody diluent (Dako, Poland), $30 \mathrm{~min}$ in room temperature, and after washing with PBS further with Hoechst 33258, 30 min, room temperature. The cells were examined under a confocal microscope (FV1000 confocal with IX81 inverted microscope, Olympus, Germany), three channel acquisition and sequential scanning was used for best resolution of signal from Hoechst 33258 and FITC fluorescence. Additionally, fluorescent images were merged with transition light images.
Quantitative Real-Time PCR Analysis (qRT-PCR) of COX-1 and COX-2 mRNA

Quantitative mRNA expression of PTGS1 (NCBI Reference Sequence: NM_000962) and PTGS2 (NM_000963) genes was performed in a two-step reverse transcription PCR. Total RNA was extracted from cells using RiboPure kit (Life Technologies, USA). After determination of the quantity and quality of isolated RNA using a NanoDrop ND-1000 spectrophotometer (NanoDrop Technologies, USA), complementary DNA (cDNA) was prepared using RevertAid First Strand cDNA Synthesis kit (Fermentas, Thermo Scientiic, Lithuania). Quantitative real-time PCR was performed in 7500 Fast Real-Time PCR System (Applied Biosystems, USA), using pre-validated Taqman Gene Expression Assays TaqMan GE Master Mix (Applied Biosystems, USA) and $1.5 \mu \mathrm{l}$ of cDNA for each reaction mix of $15 \mu \mathrm{l}$. Each sample was analyzed in two technical replicates, and mean $C_{\mathrm{T}}$ values were used for further analysis. Calculations were performed using the $\Delta \Delta C$ t relative quantification method, using 7500 Fast Real-Time PCR System Software (Applied Biosystems, USA). The thresholds were set manually to compare data between runs, and $C_{\mathrm{T}}$ values were extracted. All $C_{\mathrm{T}}$ values for each sample were normalized to the value obtained for GAPDH and HPRT1, the endogenous control gene. Fold change between groups was calculated from the means of the logarithmic expression values.

\section{Statistical Analysis}

Arithmetical means and the standard deviations $( \pm$ SD) were calculated for each of the studied quantitative parameters. The distribution of results for individual variables was obtained by Shapiro-Wilk $W$ test. As most of the distributions deviated from normal distribution, non-parametric tests were used for further analyses. To assess the differences between the used concentration of vanadium, non-parametric Wilcoxon matched pairs test and Friedmann's ANOVA were used. The obtained results were analyzed statistically using Statistica 10 (StatSoft, Poland) software, and $p$ values of less than 0.05 were considered as significant.

\section{Results}

COX-1 is the Main Source of Proinflammatory Factors After Sodium Orthovanadate Treatment

Sodium orthovanadate added to the macrophages increased $\mathrm{PGE}_{2}$ synthesis in a dose-dependent manner; however, the significant results were obtained only for $10 \mu \mathrm{M}$ vanadium solution (Fig. 1). 


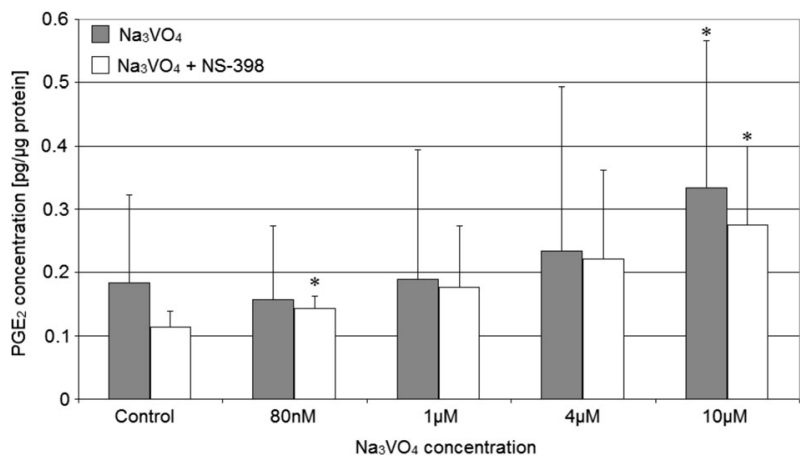

Fig. 1 The quantity of $\mathrm{PGE}_{2}$ depending on sodium orthovanadate and NS398. THP-1 macrophages were cultured with sodium orthovanadate solutions for $48 \mathrm{~h}$. After incubation, cells were scrapped and $\mathrm{PGE}_{2}$ concentration was measured by using spectrophotometric method $(n=5) .{ }^{*} p<0.05$, statistically significant as compared with control (Wilcoxon test)

Similar results were obtained for measurement of $\mathrm{TXB}_{2}$ concentration in cell cultures depending on the cultivation conditions, but in such case, sodium orthovanadate addition to the cells cause no changes in $\mathrm{TXA}_{2}$ synthesis (Fig. 2).

The addition of NS-398 - the selective COX-2 inhibitor to the macrophage culture with sodium orthovanadate caused a reduction of $\mathrm{PGE}_{2}$ and increase of $\mathrm{TXB}_{2}$ concentration vs. cultures without inhibitor, but there were no significant differences against $\mathrm{TXB}_{2}$ result for $80 \mathrm{nM}$ sodium orthovanadate $(p=0.02)$. Additionally, the increase in sodium orthovanadate concentration was followed by an increase in $\mathrm{PGE}_{2}$ synthesis (for $10 \mu \mathrm{M}$ sodium orthovanadate $p=0.04$ compared to control) and $\mathrm{TXA}_{2}$ synthesis in macrophages.

The results show that orthovanadate at concentrations used increases the quantities of $\mathrm{PGE}_{2}$ being released by macrophage cells of the THP-1 line, but the process is independent on the activity of COX-2.

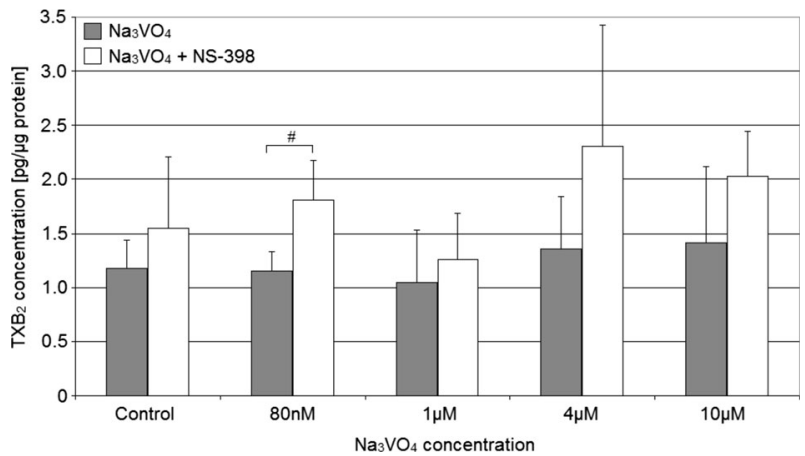

Fig. 2 The quantity of $\mathrm{TXB}_{2}$ depending on sodium orthovanadate and NS-398. THP-1 macrophages were cultured with sodium orthovanadate solutions for $48 \mathrm{~h}$. After incubation, cells were scrapped and $\mathrm{TXB}_{2}$ concentration was measured by using spectrophotometric method $(n=$ 5). $\# p<0.05$, statistically significant as compared with the experiment with NS-398 (Mann-Whitney $U$ test)
Protein Expression of COX-1 Enzyme Decreased but COX-2 Enzyme Not Changed After Sodium Orthovanadate Addition to the Cells

Sodium orthovanadate lead to a $10-15 \%$ reduction in COX-1 protein expression in macrophages cultured without NS-398 (Figs. 3 and 4). Statistically significant differences compared to control were observed for sodium orthovanadate at concentrations of $80 \mathrm{nM}(p=0.012), 1 \mu \mathrm{M}(p=0.04)$, and $4 \mu \mathrm{M}(p=0.012)$.

Addition of the NS-398 inhibitor and different concentrations of sodium orthovanadate into the culture had no effect on the expression of COX-1 protein in macrophages; however, a growing trend could be observed in COX-1 protein expression starting from sodium orthovanadate concentration of $4 \mu \mathrm{M}$.

The studied vanadium compound had no significant effect on the expression of COX-2 protein in THP-1 cells when used at any concentration; however, the addition of COX-2 inhibitor lead to a significant increase in expression that was dependent on concentration of the vanadium compound (Figs. 5 and 6). Statistically significant differences were observed for sodium orthovanadate solutions at concentrations of $4 \mu \mathrm{M}(p=0.03 ; 250 \%$ increase compared to control) and $10 \mu \mathrm{M}(p=0.03 ; 400 \%$ increase compared to control).

\section{Sodium Orthovanadate Does Not Affect mRNA Expression} of COX-1 and COX-2 Enzymes

Sodium orthovanadate has no statistically significant effect on the mRNA levels of COX-1 and COX-2 in THP-1 cells incubated with or without NS-398.

\section{Discussion}

The Effect of Sodium Orthovanadate on the Activity of COX-1 and COX-2

At concentrations used in the tests, the studied vanadium compound increases the quantities of $\mathrm{PGE}_{2}$ released into the medium by macrophages. This effect is dependent on vanadium concentration. The addition of a specific COX-2 inhibitor, NS-398, leads to a minor reduction in the amount of $\mathrm{PGE}_{2}$ being released. Sodium orthovanadate, as an inhibitor of PTP, may increase the activity of COX-2 by phosphorylating tyrosine residues within its molecule against COX-1 protein [17]. However, no change in the growing trend in $\mathrm{PGE}_{2}$ release was observed in our studies upon the use of a COX-2 inhibitor. This shows that sodium orthovanadate at concentrations used has no effect on the activity of COX-2.

The increased $\mathrm{PGE}_{2}$ release observed in our studies may be due to an increase in the activity of cPLA 2 . cPLA $\mathrm{Cl}_{2}$ acts as another, besides COX-2, checkpoint in the synthesis of $\mathrm{PGE}_{2}$. 
Fig. 3 Effect of sodium orthovanadate on COX-1 protein and COX-1 mRNA expression. Effect of vanadium solutions on a COX-1 mRNA expression and $\mathbf{b}$ COX-1 protein expression (densitometric analysis of protein normalized to $\beta$-actin); d representative Western blot in macrophages cultured with sodium orthovanadate without and with NS-398 (c and e). THP-1 macrophages were cultured with sodium orthovanadate solutions for $48 \mathrm{~h}$. After incubation, cells were harvested by scraping and mRNA was measured by using real-time PCR method $(n=3)$ and protein expression by using Western blotting method $(n=3)$. * statistically significant as compared with controls (Wilcoxon test)
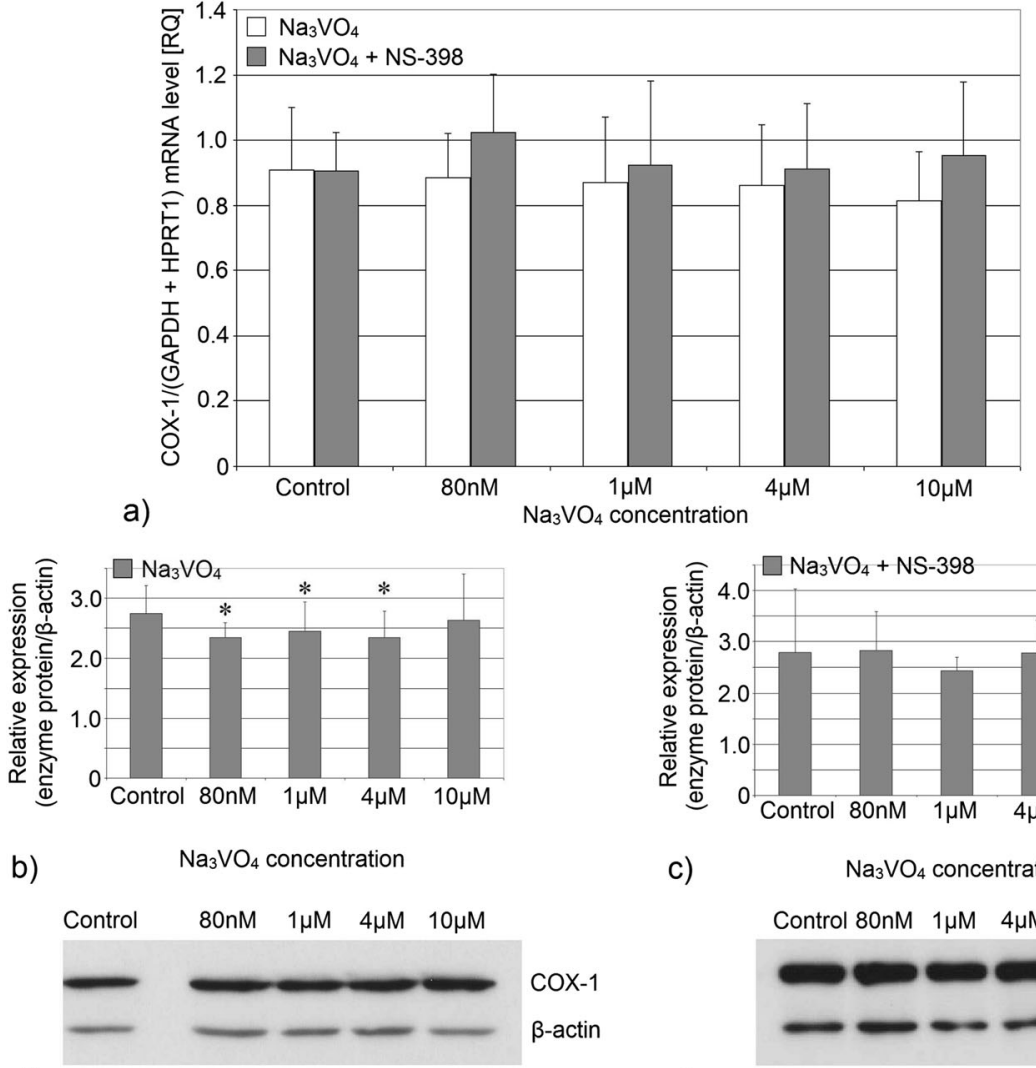

d)

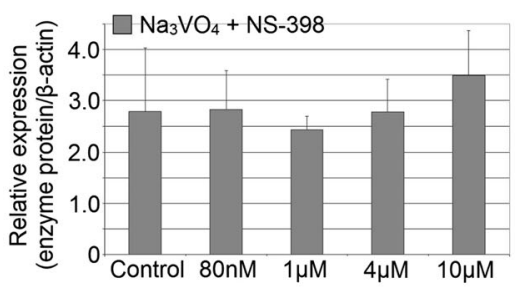

c)

$\mathrm{Na}_{3} \mathrm{VO}_{4}$ concentration

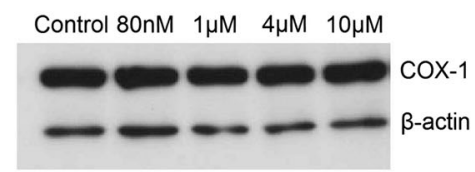

e)
By its activity, $\mathrm{cPLA}_{2}$ regulates the supply of arachidonic acid for the entire cyclooxygenase and lipoxygenase synthetic pathway. This hypothesis may find its confirmation in studies conducted in leukemia U-937 and BL-60 cell lines, revealing significant increase in the release of arachidonic acid in presence sodium vanadate at concentration of $20 \mu \mathrm{M}$ [18].

In our studies, sodium orthovanadate had no effect on the synthesis of $\mathrm{TXB}_{2}$ while the use of the inhibitor caused a statistically insignificant increase in the level of the synthesized compound. Probably, the inhibitor increased the availability of arachidonic acid for COX-1 molecules by inhibiting the activity of COX-2. The obtained results also suggest that COX-1 is the main enzyme responsible for thromboxane synthesis.

The Effect of Sodium Orthovanadate on the Expression of COX-1 and COX-2 Proteins

To date, few studies have been conducted on the effect of vanadium compounds on the expression of COX-1. In our studies, we were the first to demonstrate a ca. $10 \%$, significant reduction in COX-1 expression by micromolar concentrations of sodium orthovanadate. COX-1 is a constitutive enzyme containing an Sp1-binding motif within the $P G H S$-1 promoter and activator protein 1 (AP-1)-binding motif within intron 8 [19]. Nonetheless, it was demonstrated that at low concentrations, sodium orthovanadate might, by its effect on AP-1 and Sp1, alter the expression of COX-1, by activating the nuclear factor erythroid 2-related factor-2 (Nrf2), within ERK MAPK pathway [20]. Nrf2 is a transcription factor responsible for the expression of antioxidative and phase II detoxicative enzymes. The expression of these enzymes leads to reduced cytoplasmic levels of ROS, thus inhibition activation of JNK MAPK [21]. This may disturb the activity of AP-1 and cause Sp1 degradation [22]. This in turn cancels out the effect of ROS on increased COX-1 expression. At higher concentrations, sodium orthovanadate activates JNK MAPK and AP-1 [23, 24]. These processes cancel out the effect of vanadium compounds on Nrf2. It is probably for this reason that $10 \mu \mathrm{M}$ sodium orthovanadate causes no reduction in COX-1 expression.

In our studies, sodium orthovanadate in the presence of the inhibitor did not cause to changes in COX-1 protein expression. This might be due to the levels of 15 -deoxy- $\Delta^{12,14}$ prostaglandin $\mathrm{J}_{2}\left(15 \mathrm{~d}-\mathrm{PGJ}_{2}\right)$ being reduced by the COX-2 inhibitor, thus leading to increased activation of AP-1 [25, 26]. This process canceled out the effect of increased expression of antioxidative enzymes.

Studies conducted by Hirai et al., (1997) in human umbilical vein endothelial cells (HUVEC) showed that sodium orthovanadate had no effect on COX-1 protein expression 
Fig. 4 Imaging of COX-1 enzyme by fluorescence microscopy in macrophages cultured with sodium orthovanadate. THP-1

macrophages were cultured with sodium orthovanadate solutions for $48 \mathrm{~h}$. The immunohistochemistry was performed using specific primary antibody, mouse antiCOX-1 (the overnight incubation at $4{ }^{\circ} \mathrm{C}$ ), and secondary antibodies conjugated with fluorochrome anti-mouse IgG-FITC (incubation for $45 \mathrm{~min}$ at room temperature). The nuclei of cells were DAPI stained. Image analysis was performed with a fluorescent microscope using filters $38 \mathrm{HE}$ GFP for green fluorescence and 49 DAPI for blue fluorescence
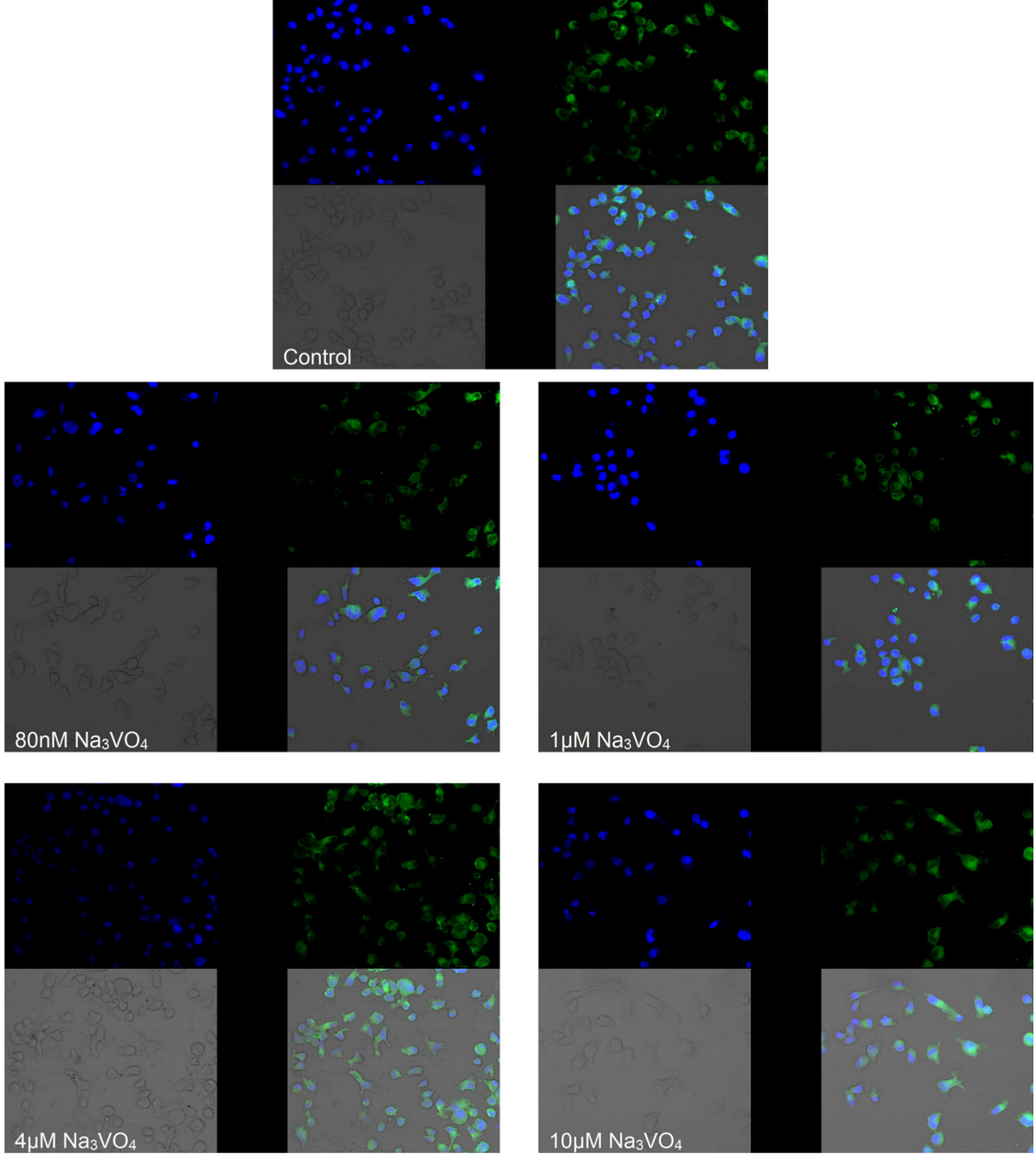

while simultaneously increasing the COX-1 mRNA levels [27]. However, the tested vanadium compound in the cited study caused such effect in an exposure time-dependent manner.

In order to better understand the effect of sodium orthovanadate in short-term (several days long) anticancer therapy and long-term antidiabetic therapy, one should thoroughly examine the effect of this compound on the expression of COX-1 protein depending on the exposure time.

In our studies, sodium orthovanadate had no significant effect on the expression of COX-2 protein within macrophages cultured without the addition of the inhibitor. However, studies conducted in non-small-cell lung carcinoma A549 cells [27] and HUVEC cells [24] revealed an increase in COX-2 protein expression, although sodium orthovanadate levels used in these studies were much higher than those used in our study [24, 27].
The use of a COX-2 inhibitor caused a significant increase in COX-2 protein expression in our study. Regulation of COX-2 protein expression is a complex process involving positive and negative feedback loops [28]. The expression of COX-2 is inhibited in an autocrine manner by $15 \mathrm{~d}^{-\mathrm{PGJ}_{2}}$ [28]. Gilroy et al., (1999) and Inoue et al., (2000) demonstrated that the use of a specific COX-2 inhibitor leads to inhibition in the activity of COX-2 and thus to reduction in $15 \mathrm{~d}_{-} \mathrm{PGJ}_{2}$ levels $[25,28] .15 \mathrm{~d}-\mathrm{PGJ}_{2}$ disturbs activation of NF-KB and its ability to bind DNA [29]. Reduced levels of this prostanoid lead to inactivation of the negative feedback loop acting on NF-KB, AP1 , and cAMP response element-binding protein (CREB), resulting in increased COX-2 expression [28-30]. These processes may occur in a peroxisome proliferator-activated receptor- $\gamma(\operatorname{PPAR} \gamma)$-dependent manner, as this receptor is present in macrophages of the THP-1 cell line [31]. Activated PPAR $\gamma$ disturbs activation of AP-1 by JNK MAPK and binds 
Fig. 5 Effect of sodium orthovanadate on COX-2 protein and COX-2 mRNA expression. Effect of vanadium solutions on a COX-2 mRNA expression and b COX-2 protein expression (densitometric analysis of protein normalized to $\beta$-actin); d representative Western blot in macrophages cultured with sodium orthovanadate without and with NS-398 (c and e). THP-1 macrophages were cultured with sodium orthovanadate solutions for $48 \mathrm{~h}$. After incubation, cells were harvested by scraping, and mRNA was measured by using real-time PCR method $(n=3)$ and protein expression by using Western blotting method $(n=3)$. * statistically significant as compared with controls (Wilcoxon test)

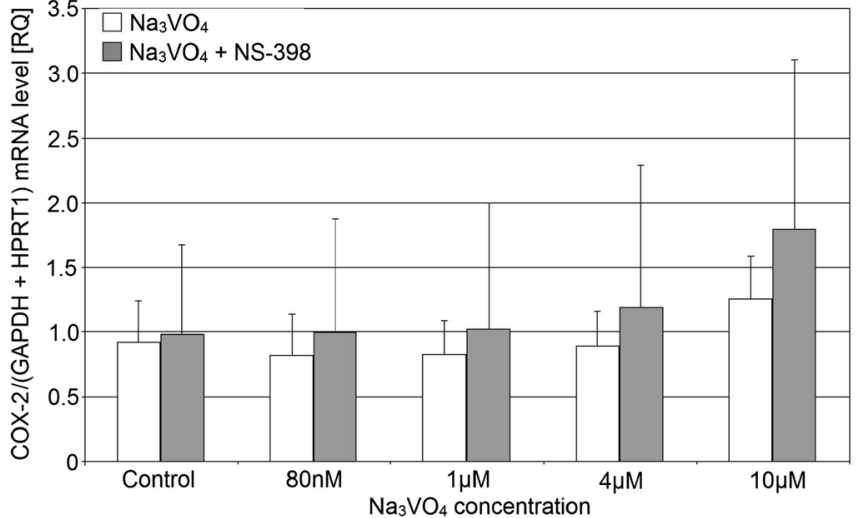

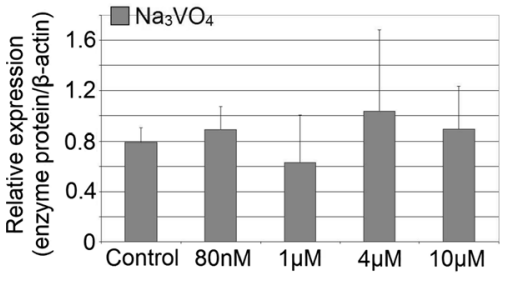

b)

$\mathrm{Na}_{3} \mathrm{VO}_{4}$ concentration

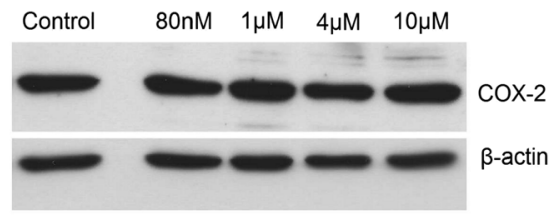

d)

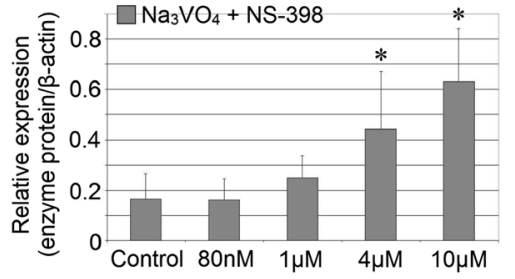

C)

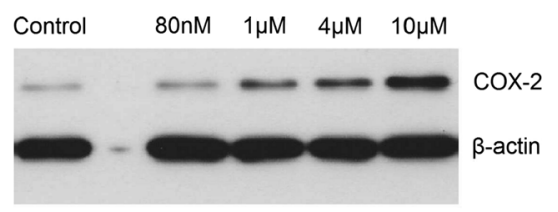

e) the cAMP response element (CBP) [26]. Activation of NF-kB caused by reduced $15 \mathrm{~d}-\mathrm{PGJ}_{2}$ levels may be intensified by the studied vanadium compound, as it was demonstrated to activate NF- $\kappa \mathrm{B}$ already at the levels of $20 \mu \mathrm{M}$ [32].

According to Murakami et al. (1997), regulation of COX-2 protein expression involves also a positive feedback loop [33]. $\mathrm{PGE}_{2}$, acting via its receptors prostaglandin $\mathrm{E}_{2}$ receptor-2 $\left(\mathrm{EP}_{2}\right)$ and prostaglandin $\mathrm{E}_{2}$ receptor-4 $\left(\mathrm{EP}_{4}\right)$, acts in an autocrine manner to increase cytoplasmic cAMP levels and thus COX-2 protein expression [28, 33]. Increased cAMP levels activate protein kinase A (PKA) which, by phosphorylating CREB protein leads to an increased COX-2 expression [34]. CREB may be additionally activated by the transduction of signal onto $\mathrm{PI} 3 \mathrm{~K}$ by activated $\mathrm{EP}_{4}$ receptor [35]. The same receptor may also increase the stability of COX-2 mRNA by activating p38 MAPK $[36,37]$.

Addition of a COX-2 inhibitor, by reducing the quantities of $\mathrm{PGE}_{2}$ being released, reduces the cellular cAMP levels thus reducing COX-2 protein expression. At the same time, sodium orthovanadate, by inhibition of the activity of PTP, affects activation of MAPK cascades, which in turn increase COX2 expression by means of AP-1 and CREB activation [38].
Combination of all of the above processes may lead to increased expression of COX-2 protein in cells cultured with a COX-2 inhibitor and sodium orthovanadate, as observed in our study. This may be of importance in combination experimental antidiabetic and anticancer therapy with the use of vanadium and non-steroidal anti-inflammatory drugs (NSAID), leading to increased COX-2 expression and enhancement of inflammatory processes.

The Effect of Sodium Orthovanadate on the mRNA levels of COX-1 and COX-2

The studied vanadium compound had no effect on the mRNA levels of COX-1 and COX-2; however, in the studies by Hirai et al. (1997), $10 \mu \mathrm{M}$ sodium orthovanadate caused an increase in the COX-1 and COX-2 mRNA depending on the HUVEC cell line incubation times [27]. The authors of the cited study observed rapid increase in mRNA levels, reaching a peak value after several hours and then returning to the baseline values [27], which might explain the lack of changes observed in the mRNA levels of COX-1 and COX-2 following $48 \mathrm{~h}$ of incubation with sodium orthovanadate. 
Fig. 6 Imaging of COX-2 enzyme by fluorescence microscopy in macrophages cultured with sodium orthovanadate. THP-1 macrophages were cultured with sodium orthovanadate solutions for $48 \mathrm{~h}$. The immunohistochemistry was performed using specific primary antibody, mouse anti-COX-2 (the overnight incubation at $4{ }^{\circ} \mathrm{C}$ ) and secondary antibodies conjugated with flouorochrome - anti-mouse IgG-FITC (incubation for $45 \mathrm{~min}$ at room temperature). The nuclei of cells were DAPI stained. Image analysis was performed with a fluorescent microscope using filters 38 HE GFP for green fluorescence and 49 DAPI for blue fluorescence
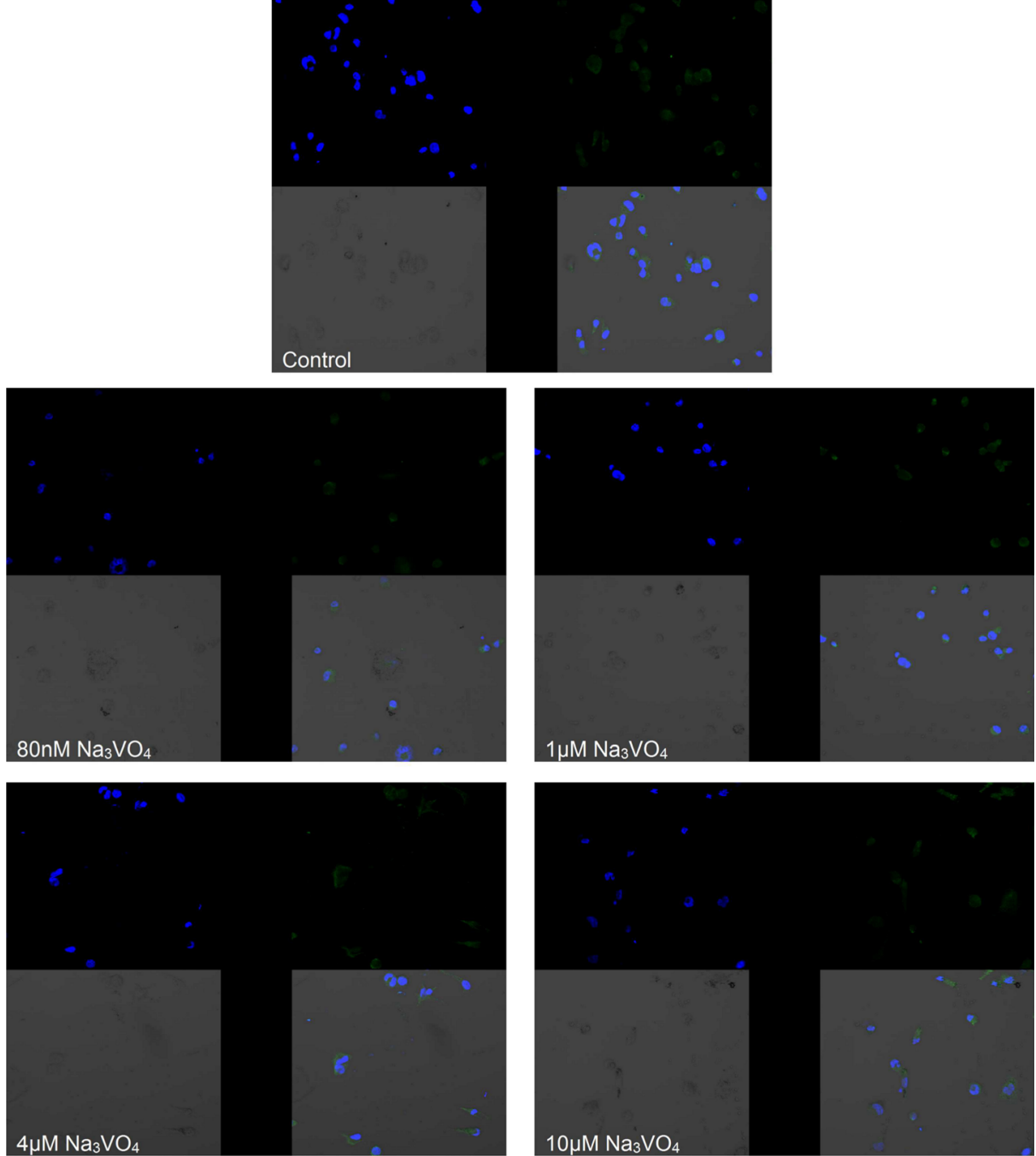

Medical Implications of the Obtained Results

The increase in the levels of $\mathrm{PGE}_{2}$ induced by sodium orthovanadate treatment was observed. In addition, orthovanadate combined with COX-2 inhibitor was shown to increase the expression of COX-2. Due to the fact that the increased activity of COX-2 promotes tumor growth, NSAID may therefore be recommended in adjuvant anticancer therapy [39, 40]. Despite the fact that increased expression of COX-2 upon the use of the inhibitor does not lead to an increase in the activity of this enzyme, sodium orthovanadate combined with NSAID may trigger cellular signaling pathways that lead to the synthesis of other proinflammatory compounds.

Understanding the mechanisms of vanadium compounds would permit to reduce the side effects of treatments being developed or question the use of the studied vanadium compounds in therapy.
Acknowledgments The Authors wish to thank their PhD students, Ms. J. Łapczuk, and Ms. A. Wajda for their help in performing qRT-PCR analyses.

Conflict of Interest The authors declare that they have no conflict of interest.

Open Access This article is distributed under the terms of the Creative Commons Attribution License which permits any use, distribution, and reproduction in any medium, provided the original author(s) and the source are credited.

\section{References}

1. Khan S, Kazi TG, Kolachi NF et al (2011) Hazardous impact and translocation of vanadium $(\mathrm{V})$ species from soil to different vegetables and grasses grown in the vicinity of thermal power plant. J Hazard Mater 190(1-3):738-743

2. Rondini EA, Walters DM, Bauer AK (2010) Vanadium pentoxide induces pulmonary inflammation and tumor promotion in a straindependent manner. Part Fibre Toxicol 7:9 
3. Zhang Z, Huang C, Li J, Shi X (2002) Vanadate-induced cell growth arrest is p53-dependent through activation of p21 in C141 cells. J Inorg Biochem 89(1-2):142-148

4. Holko P, Ligeza J, Kisielewska J, Kordowiak AM, Klein A (2008) The effect of vanadyl sulphate (VOSO4) on autocrine growth of human epithelial cancer cell lines. Pol J Pathol 59(1):3-8

5. Klein A, Holko P, Ligeza J, Kordowiak AM (2008) Sodium orthovanadate affects growth of some human epithelial cancer cells (A549, HTB44, DU145). Folia Biol (Krakow) 56(3-4):115-121

6. Cuesta S, Francés D, García GB (2011) ROS formation and antioxidant status in brain areas of rats exposed to sodium metavanadate. Neurotoxicol Teratol 33(2):297-302

7. Crans DC, Smee JJ, Gaidamauskas E, Yang L (2004) The chemistry and biochemistry of vanadium and the biological activities exerted by vanadium compounds. Chem Rev 104(2):849-902

8. Peters KG, Davis MG, Howard BW et al (2003) Mechanism of insulin sensitization by BMOV (bis maltolato oxo vanadium); unliganded vanadium (VO4) as the active component. J Inorg Biochem 96(2-3):321-330

9. Srivastava AK, Mehdi MZ (2005) Insulino-mimetic and anti-diabetic effects of vanadium compounds. Diabet Med 22(1):2-13

10. Thompson KH, Orvig C (2006) Vanadium in diabetes: 100 years from phase 0 to phase I. J Inorg Biochem 100(12):1925-1935

11. Greenhough A, Smartt HJ, Moore AE et al (2009) The COX-2/PGE2 pathway: key roles in the hallmarks of cancer and adaptation to the tumour microenvironment. Carcinogenesis 30(3):377-386

12. Auwerx J (1991) The human leukemia cell line, THP-1: a multifacetted model for the study of monocyte-macrophage differentiation. Experientia 47(1):22-31

13. Fu Y, Luo N, Lopes-Virella MF, Garvey WT (2002) The adipocyte lipid binding protein $(\mathrm{ALBP} / \mathrm{aP} 2)$ gene facilitates foam cell formation in human THP-1 macrophages. Atherosclerosis 165(2):259-269

14. Lin TS, Chang CL, Shen FM (2004) Whole blood vanadium in Taiwanese college students. Bull Environ Contam Toxicol 73(5): 781-786

15. Nandi A, Chandil D, Lechesal R et al (2006) Bifenthrin causes neurite retraction in the absence of cell death: a model for pesticide associated neurodegeneration. Med Sci Monit 12(5):BR169-BR173

16. Bradford MM (1976) A rapid and sensitive method for the quantitation of microgram quantities of protein utilizing the principle of protein-dye binding. Anal Biochem 72:248-254

17. Parfenova H, Balabanova L, Leffler CW (1998) Posttranslational regulation of cyclooxygenase by tyrosine phosphorylation in cerebral endothelial cells. Am J Physiol 274(1 Pt 1):C72-C81

18. Tsujishita Y, Asaoka Y, Nishizuka Y (1994) Regulation of phospholipase A2 in human leukemia cell lines: its implication for intracellular signaling. Proc Natl Acad Sci U S A 91(14):6274-6278

19. DeLong CJ, Smith WL (2005) An intronic enhancer regulates cyclooxygenase-1 gene expression. Biochem Biophys Res Commun 338(1):53-61

20. Kim AD, Zhang R, Kang KA, You HJ, Hyun JW (2011) Increased glutathione synthesis following Nrf2 activation by vanadyl sulfate in human chang liver cells. Int J Mol Sci 12(12):8878-8894

21. Han D, Ybanez MD, Ahmadi S, Yeh K, Kaplowitz N (2009) Redox regulation of tumor necrosis factor signaling. Antioxid Redox Signal 11(9):2245-2263

22. Chuang JY, Wang YT, Yeh SH, Liu YW, Chang WC, Hung JJ (2008) Phosphorylation by c-Jun NH2-terminal kinase 1 regulates the stability of transcription factor Sp1 during mitosis. Mol Biol Cell 19(3): $1139-1151$

23. Ding M, Li JJ, Leonard SS et al (1999) Vanadate-induced activation of activator protein-1: role of reactive oxygen species. Carcinogenesis 20(4):663-668
24. Chien PS, Mak OT, Huang HJ (2006) Induction of COX-2 protein expression by vanadate in A549 human lung carcinoma cell line through EGF receptor and p38 MAPK-mediated pathway. Biochem Biophys Res Commun 339(2):562-568

25. Gilroy DW, Colville-Nash PR, Willis D, Chivers J, Paul-Clark MJ, Willoughby DA (1999) Inducible cyclooxygenase may have antiinflammatory properties. Nat Med 5(6):698-701

26. Subbaramaiah K, Lin DT, Hart JC, Dannenberg AJ (2001) Peroxisome proliferator-activated receptor gamma ligands suppress the transcriptional activation of cyclooxygenase-2. Evidence for involvement of activator protein-1 and CREB-binding protein/ p300. J Biol Chem 276(15):12440-12448

27. Hirai K, Takayama H, Tomo K, Okuma M (1997) Protein-tyrosinekinase-dependent expression of cyclo-oxygenase-1 and -2 mRNAs in human endothelial cells. Biochem J 322(Pt 2):373-377

28. Inoue $H$, Tanabe $T$, Umesono $\mathrm{K}$ (2000) Feedback control of cyclooxygenase-2 expression through PPARgamma. J Biol Chem 275(36):28028-28032

29. Boyault S, Bianchi A, Moulin D et al (2004) 15-Deoxy-delta(12,14)prostaglandin J(2) inhibits IL-1beta-induced IKK enzymatic activity and IkappaBalpha degradation in rat chondrocytes through a PPARgamma-independent pathway. FEBS Lett 572(1-3):33-40

30. Sawano H, Haneda M, Sugimoto T, Inoki K, Koya D, Kikkawa R (2002) 15-Deoxy-delta12,14-prostaglandin J2 inhibits IL-1betainduced cyclooxygenase-2 expression in mesangial cells. Kidney Int 61(6): 1957-1967

31. Zhao G, Etherton TD, Martin KR et al (2005) Anti-inflammatory effects of polyunsaturated fatty acids in THP-1 cells. Biochem Biophys Res Commun 336(3):909-917

32. Chen F, Demers LM, Vallyathan Vet al (1999) Vanadate induction of NF-kappaB involves IkappaB kinase beta and SAPK/ERK kinase 1 in macrophages. J Biol Chem 274(29):20307-20312

33. Murakami M, Kuwata H, Amakasu Y et al (1997) Prostaglandin E2 amplifies cytosolic phospholipase A2- and cyclooxygenase-2dependent delayed prostaglandin E2 generation in mouse osteoblastic cells. Enhancement by secretory phospholipase A2. J Biol Chem 272(32):19891-19897

34. Díaz-Muñoz MD, Osma-García IC, Fresno M, Iñiguez MA (2012) Involvement of PGE2 and the cAMP signalling pathway in the upregulation of COX-2 and mPGES-1 expression in LPS-activated macrophages. Biochem J 443(2):451-461

35. Fujino H, Salvi S, Regan JW (2005) Differential regulation of phosphorylation of the cAMP response element-binding protein after activation of EP2 and EP4 prostanoid receptors by prostaglandin E2. Mol Pharmacol 68(1):251-259

36. Dean JL, Sarsfield SJ, Tsounakou E, Saklatvala J (2003) p38 Mitogen-activated protein kinase stabilizes mRNAs that contain cyclooxygenase- 2 and tumor necrosis factor AU-rich elements by inhibiting deadenylation. J Biol Chem 278(41):39470-39476

37. Faour WH, Gomi K, Kennedy CR (2008) PGE(2) induces COX-2 expression in podocytes via the $\mathrm{EP}(4)$ receptor through a PKAindependent mechanism. Cell Signal 20(11):2156-2164

38. Hirai K, Ezumi Y, Nishida E, Uchiyama T, Takayama H (1999) Comparative study of vanadate- and phorbol ester-induced cyclooxygenase- 2 expression in human endothelial cells. Thromb Haemost 82(5):1545-1552

39. Koki AT, Khan NK, Woerner BM et al (2002) Characterization of cyclooxygenase-2 (COX-2) during tumorigenesis in human epithelial cancers: evidence for potential clinical utility of COX-2 inhibitors in epithelial cancers. Prostaglandins Leukot Essent Fat Acids 66(1):13 18

40. Subbaramaiah K, Dannenberg AJ (2003) Cyclooxygenase 2: a molecular target for cancer prevention and treatment. Trends Pharmacol Sci 24(2):96-102 